\title{
Amphetamine Increases Phosphorylation of Extracellular Signal-regulated Kinase and Transcription Factors in the Rat Striatum via Group I Metabotropic Glutamate Receptors
}

\author{
Eun Sang Choe, Ph.D., Kyung Tae Chung, Ph.D., Limin Mao, M.D., and John Q. Wang, Ph.D.
}

\begin{abstract}
Amphetamine is an indirect dopamine receptor agonist and increases glutamate release in the striatum. Activation of group I metabotropic glutamate receptors ( $m$ GluRs) upregulates $C A M P$ response element-binding protein (CREB) and Elk-1 phosphorylation via extracellular signal-regulated kinase 1 and 2 (ERK1/2) in the striatum in vivo. In the present study the role of $m G l u R s$ in the regulation of ERK1/2 pathways leading to CREB and Elk-1 phosphorylation by amphetamine was investigated using immunohistochemistry and Western blot in the rat dorsal striatum. Acute administration of amphetamine ( $5 \mathrm{mg} / \mathrm{kg}$, i.p.) caused increases in phosphorylated ( $p) C R E B, p E l k-1$, and $p E R K 1 / 2$ immunoreactivity. Intrastriatal blockade of group I $m G l u R s$ with N-phenyl-7-(hydroxyimino)cyclopropa[b]chromen-1acarboxamide (PHCCC; $25 \mathrm{nmol}$ ) significantly attenuated amphetamine-induced $p C R E B, p E l k-1, p E R K 1 / 2$, and Fos immunoreactivity in both medial and lateral areas of the striatum. Systemic injection of an mGluR5 antagonist,
\end{abstract}

2-methyl-6-(phenylethynyl)pyridine hydrochloride (MPEP; $10 \mathrm{mg} / \mathrm{kg}$, i.p.), also blocked the amphetamine induction of these phosphoproteins. In contrast, intrastriatal blockade of group II/III mGluRs with (RS)- $\alpha$-methylserine-o-phosphate monophenyl ester (MSOPPE; $25 \mathrm{nmol}$ ) did not affect amphetamine-induced increases in all the four markers. Similarly, intrastriatal dantrolene (2 or $20 \mathrm{nmol}$ ) that blocks intracellular $\mathrm{Ca}^{2+}$ release from ryanodine-sensitive stores did not affect amphetamine effects. Injection of PHCCC, MPEP, MSOPPE, or dantrolene alone did not alter basal levels of the three phosphoproteins and Fos. These data suggest that acute amphetamine is able to facilitate the phosphorylation of CREB, Elk-1, and ERK1/2 signaling proteins and Fos gene expression via a group I $m G l u R$-dependent mechanism in the dorsal striatum.

[Neuropsychopharmacology 27:565-575, 2002] (C) 2002 American College of Neuropsychopharmacology. Published by Elsevier Science Inc.
From the Division of Pharmacology (ESC, LM, JQW), School of Pharmacy, University of Missouri-Kansas City, 2411 Holmes St. M3-C15, Kansas City, MO 64108, USA; and Department of Tumor Cell Biology (KTC), St. Jude Children's Research Hospital, 332 North Lauderdale St., Memphis, TN 38105, USA.

Address correspondence to: John Q. Wang, Ph.D., Division of Pharmacology, School of Pharmacy, University of Missouri-Kansas City, 2411 Holmes St., M3-225, Kansas City, MO 64108. Tel.: (816) 235-1786; Fax: (816) 235-1776; E-mail: wangjq@umkc.edu

Received November 27, 2001; revised March 18, 2002; accepted April 1, 2002.

Online publication: 4/03/02 at www.acnp.org/citations/ Npp040302277.
KEY WORDS: Calcium; CREB; Dopamine; Drugs of abuse; ERK; Elk-1; Fos

Amphetamine, an indirect dopamine receptor agonist, increases glutamate release in the striatum (Nash and Yamamoto 1993; Del Arco et al. 1999; Rawls and McGinty 2000). Activation of metabotropic glutamate receptors (mGluRs) transduces extracellular glutamatergic signals to second messengers in a subtype-specific manner. Activation of group I mGluRs (mGluR1/5) mobilizes intracellular $\mathrm{Ca}^{2+}$ release (Dale et al. 2001; Kawa- 
bata et al. 1998; Schnabel et al. 1999) and activates mitogen-activated protein kinases (MAPK) (Choe and Wang 2001). In contrast, activation of group II/III receptors downregulates the adenylate cyclase (AC) and cyclic adenosine monophosphate (cAMP) cascades. Previous studies show that mGluRs are involved in the regulation of amphetamine-induced behaviors in a subgroup specific manner (Cartmell et al. 1999, 2000; Mao and Wang 1999, 2000; Mao et al. 2000; Spooren et al. 2000).

Cyclic AMP response element-binding protein (CREB) and Elk-1 are major transcriptional regulators in striatal projection neurons and are phosphorylated by one member of MAPK family: extracellular signal-regulated kinase 1/2 (ERK1/2) (Sgambato et al. 1998; Vanhoutte et al. 1999). Stimulation of group I mGluRs with the selective agonist, 3,5-dihydroxyphenylglycine (DHPG), upregulates CREB, Elk-1, and ERK1/2 phosphorylation in the dorsal striatum (Choe and Wang 2001). Like DHPG, amphetamine increases CREB phosphorylation in the striatum (Konradi et al. 1994). Numerous studies show that CREB is necessary for c-fos mRNA induction by amphetamine, and Fos protein is induced by glutamatergic signals (Konradi et al. 1994; Vanhoutte et al. 1999). A recent study also shows that cocaine or methamphetamine increases pERK1/2 immunoreactivity (IR) in the striatum (Adams et al. 2001). These findings suggest that both dopaminergic and glutamatergic inputs are capable of regulating the ERK1/2 signaling pathways leading to the phosphorylation of CREB and Elk-1 and thus gene expression in striatal neurons. However, the role of mGluRs in regulating ERK1/2 pathways leading to CREB and Elk-1 phosphorylation in response to dopamine stimulation remains to be documented.

In this study, potential roles of group I mGluRs were therefore examined by investigating whether amphetamine upregulates CREB, Elk-1 and ERK1/2 phosphorylation and Fos expression via a group I mGluRdependent way in striatal neurons. Experiments were performed in freely moving rats treated with: (1) an acute injection of amphetamine; (2) intrastriatal infusion of the group I selective antagonist, n-phenyl-7-(hydroxyimino) cyclopropa[b]chromen-1a-carboxamide (PHCCC), followed by an acute amphetamine injection; (3) intrastriatal infusion of the group II/III selective antagonist, (RS)- $\alpha$ methylserine-o-phosphate monophenyl ester (MSOPPE), followed by an acute amphetamine injection; (4) systemic injection of the mGluR5 selective antagonist 2-methyl-6(phenylethynyl)pyridine hydrochloride (MPEP), followed by an acute amphetamine injection; and (5) intrastriatal infusion of the ryanodine receptor antagonist, dantrolene, followed by an acute amphetamine injection. Immunohistochemistry and Western blot were applied to quantify alterations in the levels of the phosphorylated or unphosphorylated signaling molecules in the selected areas of ipsilateral dorsal striatum.

\section{METHODS}

\section{Animals}

Adult male Wistar rats (200-250 g) were obtained from Charles River Laboratories (New York, NY). Rats were individually housed in a controlled environment during all experimental treatments. Food and water were provided ad libitum and rats were maintained on a 12/12-h light/dark cycle (lights on at 7:00 A.M.). On the day of the experiment injection was made in the quiet room to minimize stress. All animal use procedures were approved by the Institutional Animal Care and Use Committee and were accomplished in accordance with the provisions of the NIH Guide for the Care and Use of Laboratory Animals.

\section{Drugs}

All pharmacological drugs were purchased from Tocris Cookson (Ballwin, MO) except for D-amphetamine (Sigma, St. Louis, MO) and freshly prepared on the day of the experiment. PHCCC, MSOPPE, MPEP, and dantrolene were dissolved in dimethylsulfoxide (DMSO), and then diluted in artificial cerebrospinal fluid (aCSF) (in mM: $\mathrm{NaCl} 123, \mathrm{CaCl}_{2} 0.86, \mathrm{KCl} 3.0, \mathrm{MgCl}_{2}$ 0.89, $\mathrm{NaH}_{2} \mathrm{PO}_{4} 0.50$ and $\mathrm{Na}_{2} \mathrm{HPO}_{4} 0.25$ aerated with $95 \%$ $\mathrm{O}_{2} / 5 \% \mathrm{CO}_{2}, \mathrm{pH}$ 7.2-7.4). Amphetamine was directly dissolved in $0.9 \%$ saline. DMSO in combination with aCSF was therefore used as vehicle control for the respective agents. Solutions of all drugs were neutralized to $\mathrm{pH}$ 7.2-7.4 with ${ }_{1 \mathrm{~N}} \mathrm{NaOH}$, if necessary.

\section{Experimental Design}

Five separate experiments were conducted in this study. The first and second experiments investigated whether amphetamine upregulates the phosphorylation of MAPKs (ERK1/2 and p38) and downstream transcription factors CREB and Elk-1 using immunohistochemistry and Western blot. Rats were randomly divided into two groups ( $n=4-5$ per group). Each rat received one intraperitoneal (i.p.) injection of saline or amphetamine $(5 \mathrm{mg} / \mathrm{kg})$. The third experiment detected whether group I mGluRs mediate amphetamine-stimulated CREB, Elk-1 and ERK1/ 2 phosphorylation and Fos induction using immunohistochemistry. Rats were randomly divided into six groups $(\mathrm{n}=4-5$ per group). PHCCC $(25 \mathrm{nmol})$ or MSOPPE (25 nmol) was infused into the center of the striatum $30 \mathrm{~min}$ prior to an acute amphetamine injection ( $5 \mathrm{mg} / \mathrm{kg}$, i.p.). The fourth experiment examined whether mGluR5, a group I subtype that is highly expressed in medium spiny projection neurons (Testa et al. 1994), participates in the mediation of amphetamine actions. Effects of the systemically active mGluR5 antagonist MPEP (i.p. injection; 30 min prior to amphetamine) on amphetamine ac- 
tions were tested in different groups of rats $(n=4$ per group). Finally, a fifth experiment was conducted to evaluate the role of intracellular $\mathrm{Ca}^{2+}$ release in the group I-sensitive signaling pathway regulating the phosphoproteins. Group I mGluRs are known to stimulate phospholipase $C$ resulting in increased 1,4,5-triphosphate $\left(\mathrm{IP}_{3}\right) . \mathrm{IP}_{3}$ could then stimulate $\mathrm{IP}_{3}$ receptors on internal $\mathrm{Ca}^{2+}$ stores to release $\mathrm{Ca}^{2+}$. However, at present, agents that interact with $\mathrm{IP}_{3}$ receptors are not suitable for the in vivo study due to the lack of permeability in intact cells and characterizations (such as heparin). We then used a systemically active and membrane-permeable agent dantrolene to test the possible participation of ryanodine receptorsensitive $\mathrm{Ca}^{2+}$ release to amphetamine actions. Dantrolene ( 2 or $20 \mathrm{nmol}$ ) that blocks intracellular $\mathrm{Ca}^{2+}$ release from the ryanodine-sensitive stores was infused into the center of the striatum $30 \mathrm{~min}$ prior to an acute amphetamine injection in different groups of rats $(n=4-5$ per group). The selection of $20 \mathrm{nmol}$ of dantrolene was based on our previous finding that intracaudate injection of the agent at this dose was able to attenuate DHPG-stimulated motor activity (Wang and Mao 2000). This indicates a role of ryanodine-sensitive $\mathrm{Ca}^{2+}$ release in behavioral effects of DHPG, even though group I mGluRs are considered to be directly linked to $\mathrm{IP}_{3}$-sensitive $\mathrm{Ca}^{2+}$ release.

\section{Surgery and Intrastriatal Injection}

Rats were anesthetized with $8 \%$ chloral hydrate $(5.8 \mathrm{ml} /$ $\mathrm{kg}$, i.p.) and placed in a Kopf stereotaxic apparatus. Under aseptic conditions, a 23-gauge stainless steel guide cannula (inner diameter: $0.29 \mathrm{~mm}, 10 \mathrm{~mm}$ in length) was implanted at the coordinates of $1 \mathrm{~mm}$ anterior to bregma, $2.5 \mathrm{~mm}$ right to midline, and $3 \mathrm{~mm}$ below surface of skull. The guide cannula was sealed with a stainless steel wire of the same length $(10 \mathrm{~mm})$. Rats were allowed five days to recover from surgery. On the day of the experiment, the inner steel wire was replaced by a 30-gauge stainless steel injection cannula (inner diameter: 0.15 $\mathrm{mm}$ ) with a length of $12.5 \mathrm{~mm}$ that protruded $2.5 \mathrm{~mm}$ beyond the guide cannula. Through the injection cannula drug was infused unilaterally into the central part of the right dorsal striatum in a volume of $1 \mu \mathrm{l}$ at a rate of $0.2 \mu \mathrm{l} / \mathrm{min}$ in freely moving rats. Progress of injection was monitored by observing movement of a small air bubble through a length of precalibrated PE-10 tubing inserted between the injection cannula and a $2.5 \mu \mathrm{l}$ Hamilton microsyringe. After completion of injection, the injector was left in place for an additional $5 \mathrm{~min}$ to reduce any possible backflow of the solution along the injection tract. All injections were made in home cage.

\section{Western Blot}

Rats were deeply anesthetized with Equithesin $(5 \mathrm{ml} /$ $\mathrm{kg}$, i.p.) and decapitated $30 \mathrm{~min}$ after saline or amphet-
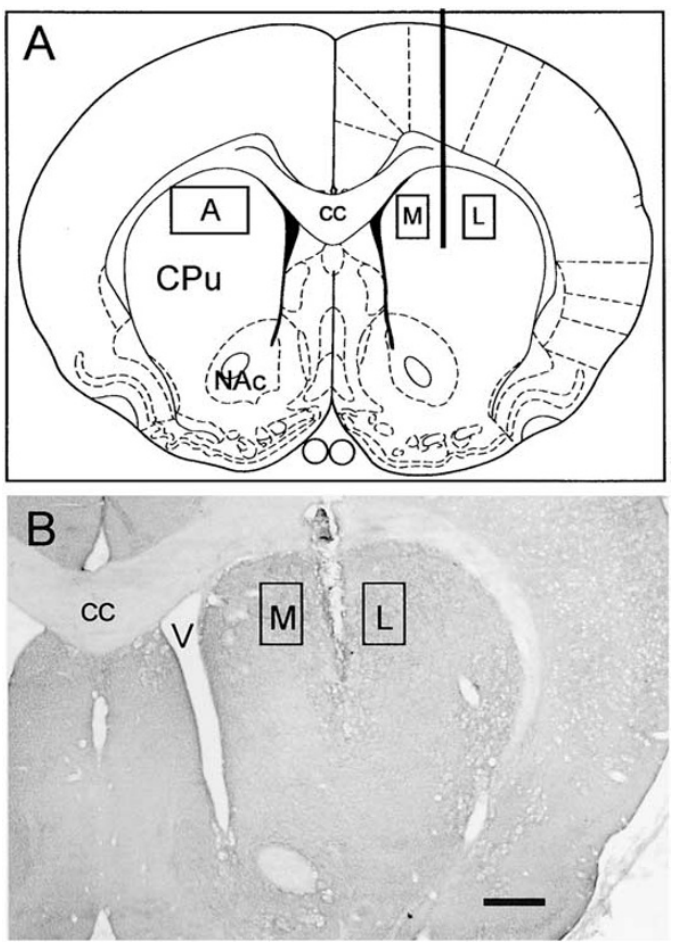

Figure 1. A schematic diagram (panel A) and a striatal section immunostained with pCREB antibody (panel B) illustrating the microinjection tract and three areas (rectangles) measured for quantification. A vehicle solution was infused unilaterally into the center of right dorsal striatum followed by an i.p. injection of amphetamine at a dose of $5 \mathrm{mg} / \mathrm{kg}$ (panel B). The rectangle A represents the area measured in experiments 1 and 4 . The rectangles $\mathrm{M}$ and $\mathrm{L}$ are the areas measured in experiments 2,3 , and 5 . CPu, caudate-putamen; Nac: nucleus accumbens; cc: corpus callosum; V: lateral ventricle. Scale bar $=0.5 \mathrm{~mm}$.

amine injection. Brains were removed and frozen in isopentane at $-40^{\circ} \mathrm{C}$ and stored in a deep freezer. Sixty micrometer sections were cut in a cryostat and overall dorsal striatum was removed with a steel borer (inner diameter: $\sim 2 \mathrm{~mm}$ ). Three tissue samples per brain were lysed in SDS sample buffer for $5 \mathrm{~min}$ at $95^{\circ} \mathrm{C}$. The samples were then sonicated for $30 \mathrm{~s}$ on ice and centrifuged for $10 \mathrm{~min}$ at 14,000 rpm with an Eppendof tabletop centrifuge. The supernatants were resolved using $10 \%$ SDS-PAGE and transferred to nitrocellulose membrane. The membrane was blocked with blocking buffer $(0.1 \%$ gelatin, $15 \mathrm{mM}$ Tris-HCl, pH7.5, $1 \mathrm{mM}$ EDTA, $0.1 \%$ Triton $\mathrm{X}-100,130 \mathrm{mM} \mathrm{NaCl}$, and $0.002 \% \mathrm{NaN}_{3}$ ). The membrane was probed with each primary antibody overnight at room temperature: PCREB $(1: 2,000)$, CREB $(1: 2,000)$, pERK1/2 (p-p44/42 MAPK, 1:2,000), ERK1/2 (1:2,000), p-p38 MAPK $(1: 2,000)$, and p38 MAPK $(1: 2,000)$. All of the primary antibodies were purchased from Cell Signaling Technology (Beverly, MA). The membrane was then incubated with appropriate secondary antibodies. Unphosphorylated proteins were probed after stripping 


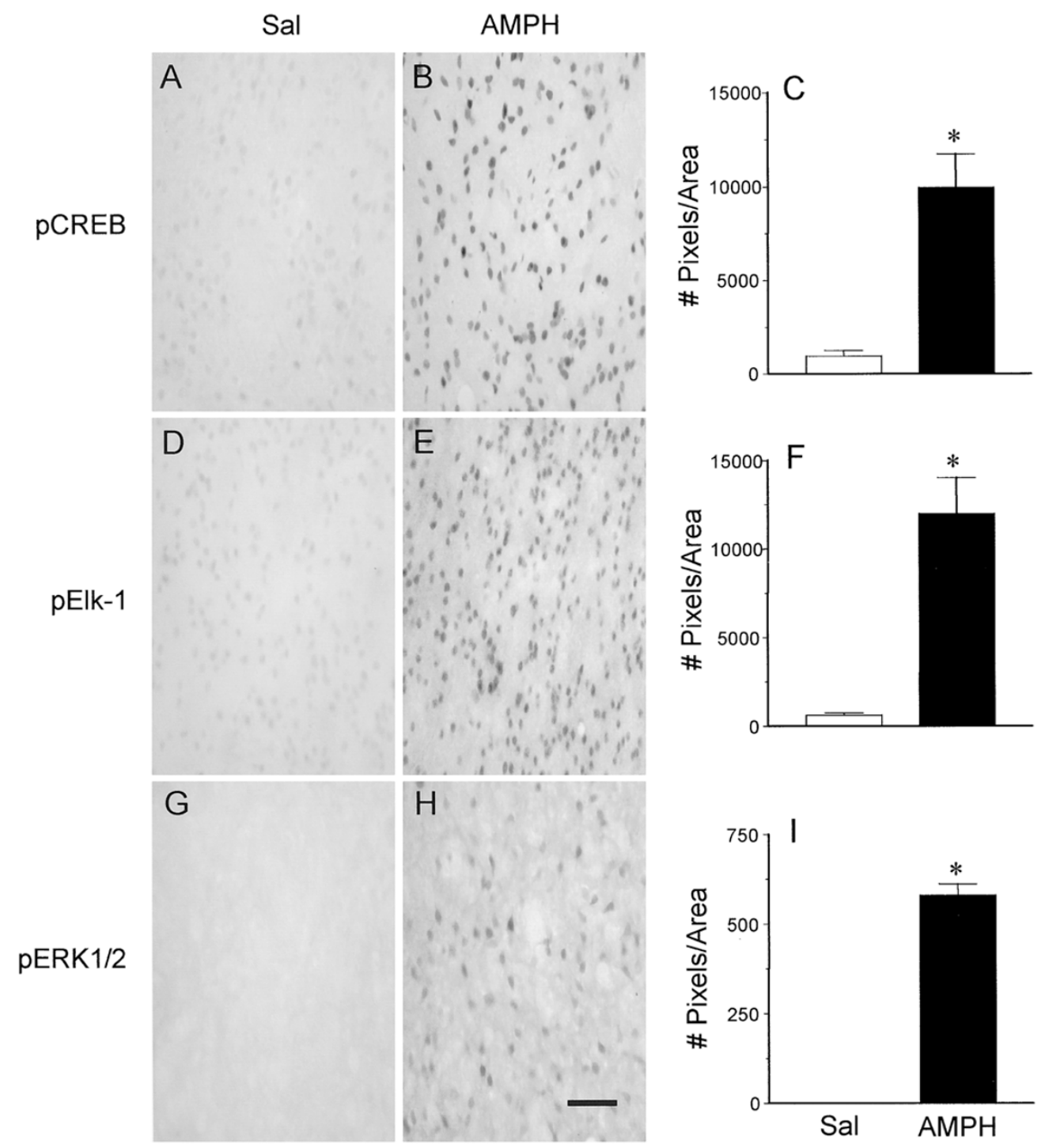

Figure 2. Effects of an acute injection of amphetamine on pCREB (A-C), pElk-1 (D-F), and pERK1/2 (G-I) induction in striatal neurons. A, D, and G: saline (Sal); B, E, and H: amphetamine (AMPH, $5 \mathrm{mg} / \mathrm{kg}$, i.p.). Scale bar represents $150 \mu \mathrm{m}$. Semi-quantitative analysis showed that amphetamine significantly increased pCREB (C), pElk-1 (F), and pERK1/2 (I) immunoreactivity in striatal neurons $\left(\mathrm{n}=4-5\right.$ per group). ${ }^{*} p<.001$ as compared with saline groups.

the same membrane that has been probed for phosphorylated proteins. Immunoreactive protein bands were detected by enhanced chemiluminescence reagents (ECL; Amersham Pharmacia Biotech, Piscataway, NJ) on an X-ray film.

\section{Immunohistochemistry}

Thirty minutes after the final injection, rats were deeply anesthetized with Equithesin $(5 \mathrm{ml} / \mathrm{kg}$, i.p.), and transcardially perfused with $4 \%$ paraformaldehyde at $4^{\circ} \mathrm{C}$. The 30 -min survival time was chosen based on previous studies on the kinetics of CREB phosphorylation in vivo (Choe and McGinty 2000, 2001). Brains were removed and postfixed in $10 \%$ su- crose $/ 4 \%$ paraformaldehyde for $2 \mathrm{~h}$ at $4^{\circ} \mathrm{C}$ and then placed in $20 \%$ sucrose/PBS at $4^{\circ} \mathrm{C}$ overnight. Using a cryostat microtome, $40 \mu \mathrm{m}$ frozen sections were cut. Two sections per antiserum per brain were collected at striatal levels and processed for immunohistochemistry. P-CREB antiserum $(1: 1,000)$ recognizes the CREB phosphoprotein surrounding amino acid Ser133. P-Elk-1 antiserum $(1: 6,000)$ detects Elk-1 protein only when phosphorylated at amino acid Ser383. P-p44/42 MAPK antiserum (1:500) detects ERK1 and ERK2 only when catalytically activated by phosphorylation at Thr202 and Tyr204. All of the primary antibodies listed above were purchased from Cell Signaling Technology. Sections were incubated with each antiserum for $20 \mathrm{~h}$ at $4^{\circ} \mathrm{C}$ on a shaker. Sections were then incubated in goat 

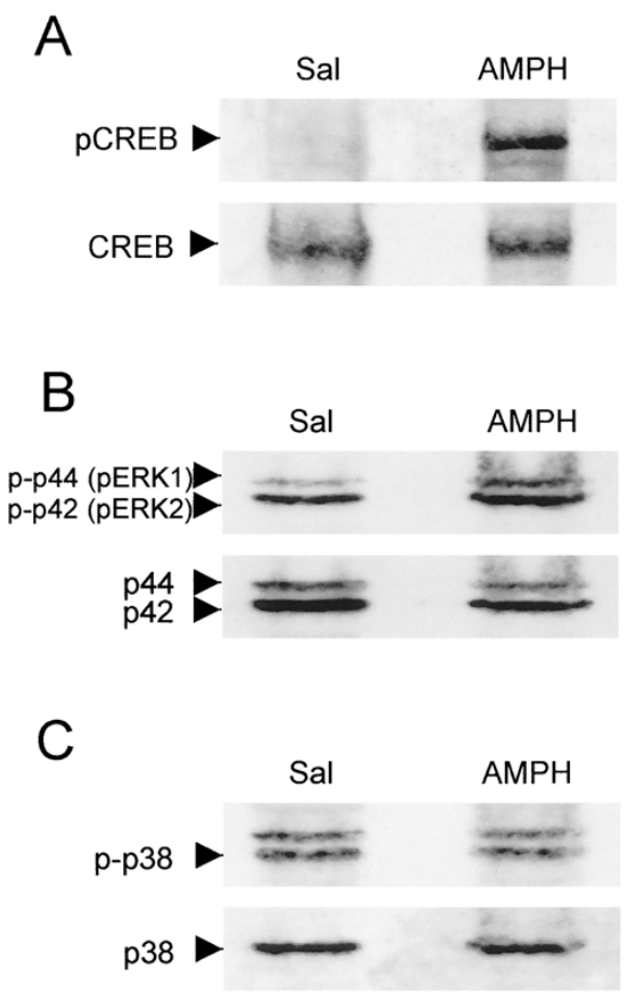
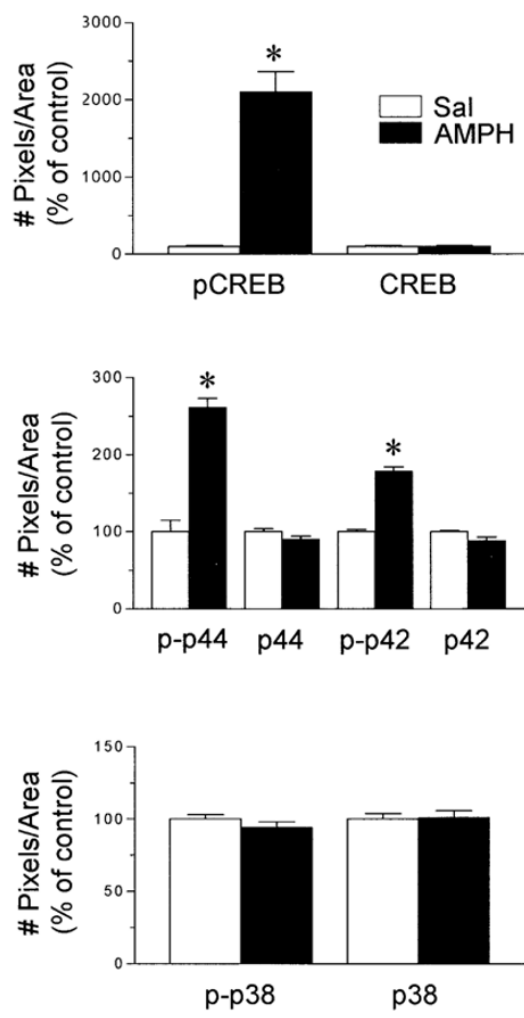

Figure 3. Western immunoblot analysis of the effect of an acute amphetamine injection on PCREB (A), pERK1/2 (B, p-p44 = pERK1 and $\mathrm{p}$-p42 $=\mathrm{pERK} 2)$, and $\mathrm{p}-\mathrm{p} 38$ MAPK (C) induction in striatal neurons. Semi-quantitative analysis showed that amphetamine (AMPH, $5 \mathrm{mg} / \mathrm{kg}$, i.p.) caused increases in the immunoreactivity of $\mathrm{pCREB}$ and $\mathrm{pERK} 1 / 2$, but not p-p38 MAPK, in striatal neurons (n $=4-5$ per group). ${ }^{*} p<.001$ as compared with saline groups. anti-rabbit secondary antiserum (Vector Labs, Burlingame, CA) for $1 \mathrm{~h}$ followed by avidin-biotin-peroxidase reagents (Elite Vectastain kit, Vector Labs) for $1 \mathrm{~h}$ at room temperature. Diaminobenzidine was used as the chromagen and $\mathrm{NiCl}_{2}$ was added to enhance reaction product. In previous studies, the pCREB, pElk-1, pERK1/2, or Fos antiserum was adsorbed with pCREB, pElk-1, pERK1/2, or Fos peptide and immunostaining was blocked (Simpson et al. 1995; Choe and McGinty 2000). As a control for pCREB-IR, CREB-IR was not induced by a cAMP analog or group I mGluR agonist (Choe and McGinty 2000; Choe and Wang 2001).

\section{Quantitation of Immunoreactivity}

Immunoreactive protein bands on X-ray films were semi-quantified using an Imaging CCD camera and $\mathrm{NIH}$ Image 1.62 software. Briefly, film background was measured and saved as a "blank field" to correct uneven illumination. The upper limit of the density slice option was set to eliminate any background, and this value was used to measure all images. The lower limit was set at the bottom of the LUT scale. The immunoreactive protein bands were measured using a rectangle covered the individual band. Similarly, levels of pCREB, pElk-1, pERK1/2, or Fos IR in the dorsal striatum were semi-quantified using a modified procedure from Simpson et al. (1995). Briefly, immunoreactive images were captured from a Nikon photomicroscope using an Imaging CCD camera and NIH Image 1.62 software. For the first and fourth experiment, using a 10x objective, the immunoreactivity in two sections per brain stained with each antiserum was measured in a $640 \times 480$ pixel area in the right dorsal striatum (rectangle A in Figure 1). For the second, third, and fifth experiments, a $480 \times 300$ pixel area was used to measure the immunoreactivity of the markers in the medial or lateral areas of the ipsilateral dorsal striatum (rectangles $\mathrm{M}$ and $\mathrm{L}$ in Figure 1). The areas analyzed for quantification were held constant for all experiments. The density threshold was adjusted so that background staining in white matter regions was eliminated and the number of immunoreactive pixels per selected area was measured above this threshold. The number of immunoreactive pixels represents all counted pixels over all positive staining cells in an area surveyed, which closely reflects changes in the number of cells immunoreactive to a given marker.

\section{Statistics}

Statistical significance of the number of immunoreactive pixels per measured area between groups was determined using a 1-way ANOVA on ranked data followed by a Tukey's HSD (honestly significant difference) test in SAS (Cary, NC). Statistically significant level was taken as $p<.05$. 


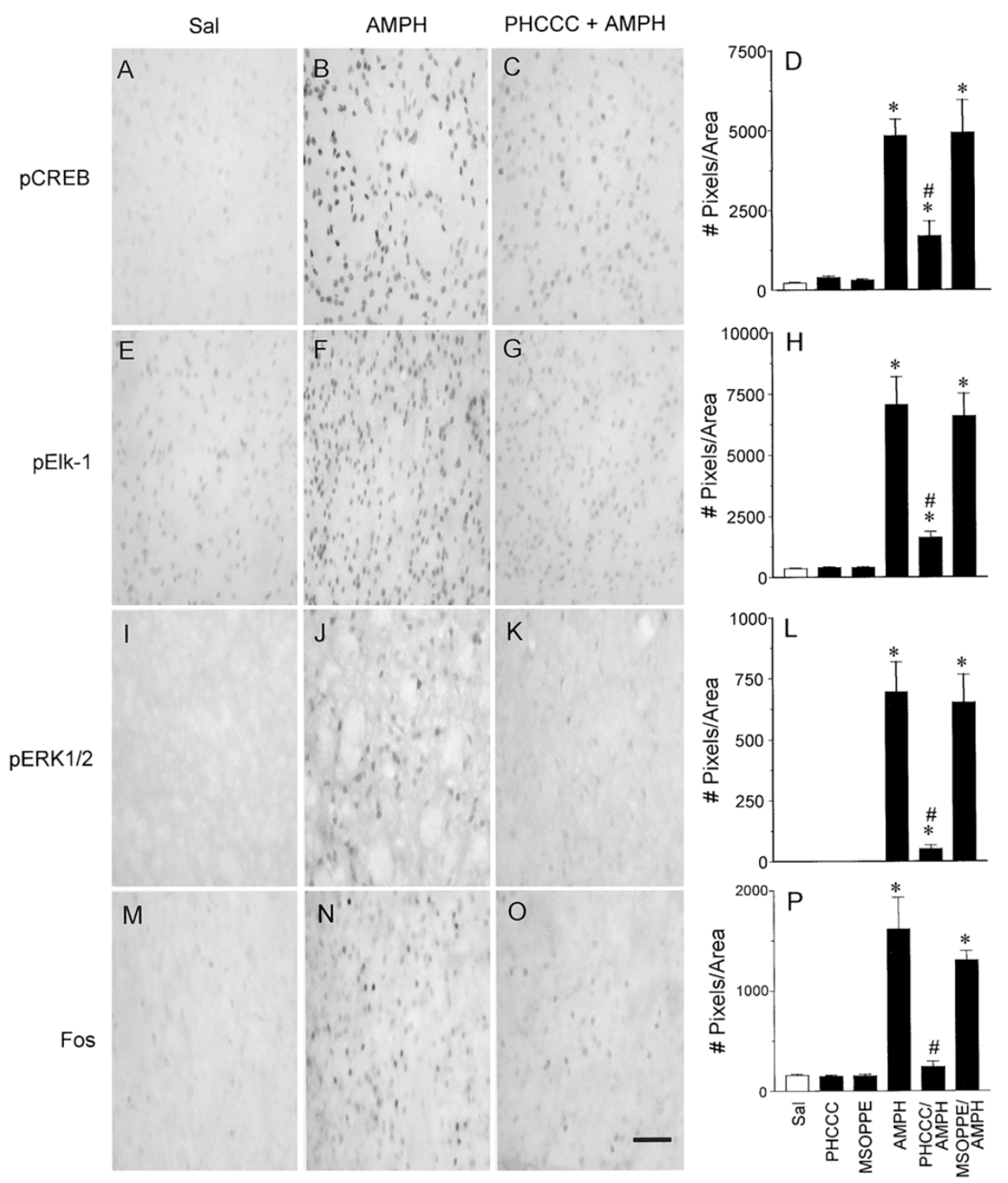

Figure 4. Effects of unilateral intrastriatal infusion of PHCCC or MSOPPE on an acute amphetamine-stimulated pCREB (A-D), pElk-1 (E-H), pERK1/2 (I-L), and Fos (M-P) induction in the medial area of the striatum. A, E, I, and M: saline; B, F, J, and N: amphetamine (AMPH, $5 \mathrm{mg} / \mathrm{kg}$, i.p.); C, G, K, and O: PHCCC (25 nmol) + AMPH. The right lateral ventricle is on the left margin of each image. Scale bar represents $150 \mu \mathrm{m}$. Semi-quantitative analysis showed that PHCCC, but not MSOPPE (25 nmol), attenuated amphetamine-induced pCREB (D), pElk-1 (H), pERK1/2 (L), and Fos (P) immunoreactivity in the striatum ( $\mathrm{n}=4-5$ per group). ${ }^{*} p<.001$ as compared with saline group; ${ }^{\#} p<.001$ as compared with amphetaminetreated group.

\section{RESULTS}

\section{Amphetamine Increased pCREB, pElk-1, and pERK1/2, But Not p-p38, Immunoreactivity}

Immunohistochemical studies demonstrated low basal levels of pCREB (Figure 2, panel A) and pElk-1 (Figure 2 , panel D) IR in rat treated with saline. The pERK1/2 IR was not detectable after saline treatment (Figure 2, panel G). The pCREB (Figure 2, panel B), pElk-1 (Figure 2, panel E), and pERK1/2 (Figure 2, panel H) IR were significantly increased by an acute amphetamine injection ( $5 \mathrm{mg} / \mathrm{kg}$, i.p.) as compared with controls. Induction of pCREB and pElk-1 IR by amphetamine was exclusively confined to the nuclear compartments of striatal neurons, whereas pERK1/2 IR was detected in both nuclear and cytoplasmic compartments. Semiquantitative analysis confirmed that amphetamine increased the immunoreactivity of all the three phosphoproteins detected by immunohistochemistry (Figure 2, panels C, F and I). Parallel to the immunohistochemical data, Western immunoblot showed that pCREB (Figure 3, panel A) and pERK1/2 (Figure 3, panel B) IR 

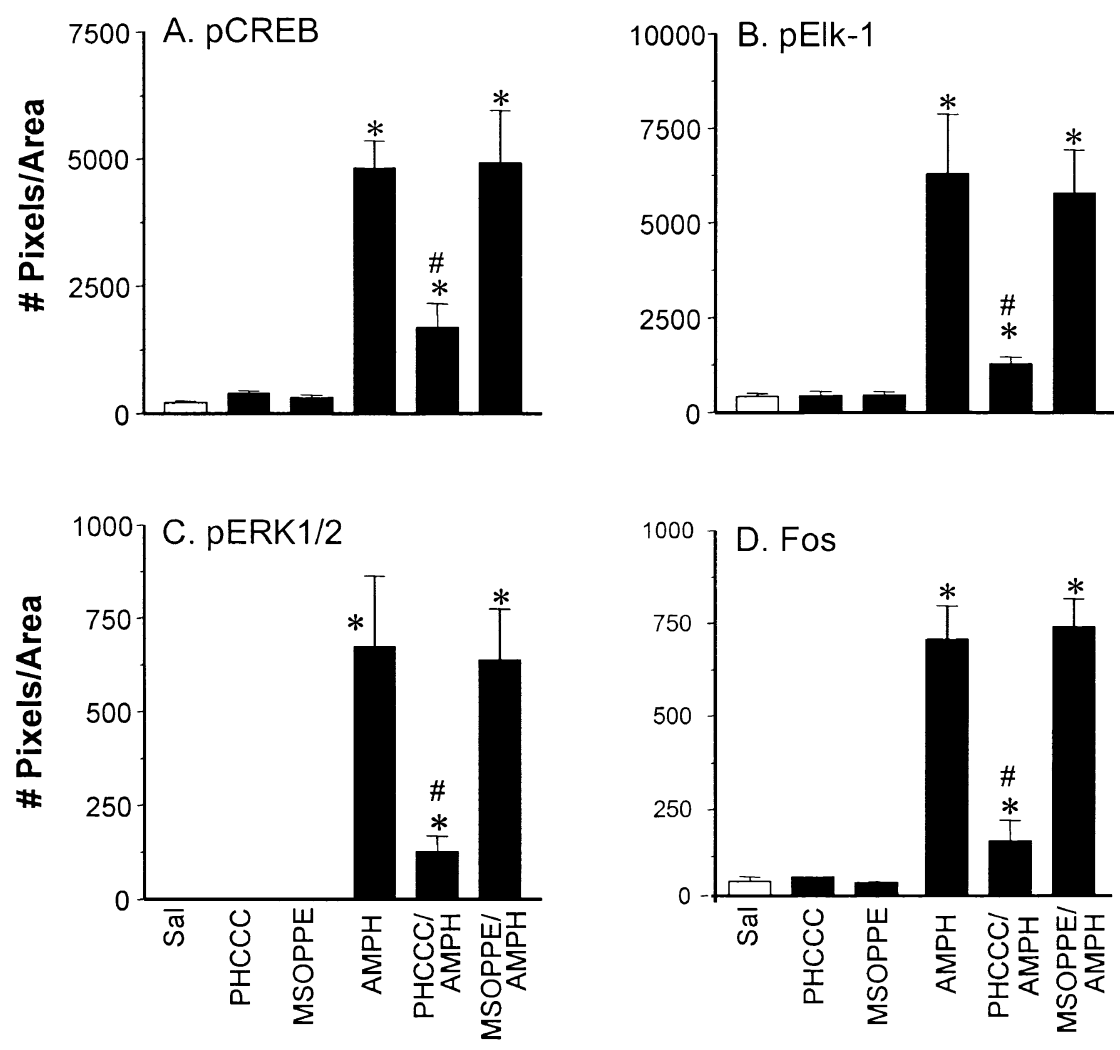

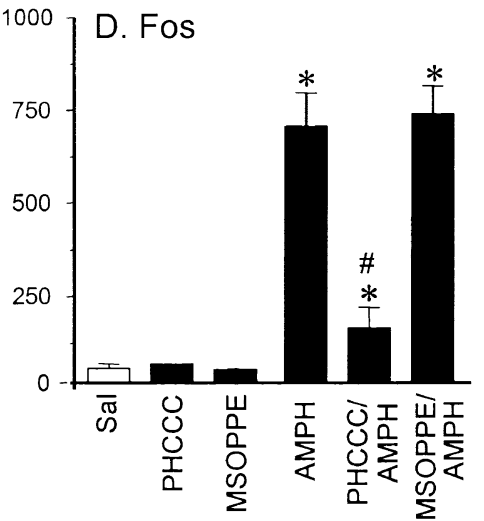

Figure 5. Semi-quantitative analysis of the effect of unilateral intrastriatal infusion of PHCCC or MSOPPE on an acute amphetamine-stimulated pCREB (A), pElk-1 (B), pERK1/2 (C), and Fos (D) induction in the lateral area of the striatum ( $\mathrm{n}=4-5$ per group). Intrastriatal PHCCC (25 nmol) or MSOPPE (25 $\mathrm{nmol})$ was given alone or $30 \mathrm{~min}$ prior to amphetamine (5 $\mathrm{mg} / \mathrm{kg}$, i.p.). Note that PHCCC, but not MSOPPE, significantly decreased amphetamine-stimulated immunoreactivity of all the markers. ${ }^{*} p<$ .001 as compared with saline group; ${ }^{\#} p<$ .001 as compared with amphetaminetreated group. was significantly increased by a single amphetamine injection. However, p-p38 MAPK IR was not altered by amphetamine (Figure 3, panel C). We have attempted to perform Western blot with anti-Elk-1 antisera. However, the data revealed that these antisera were not suitable for the immunoblotting.

\section{PHCCC, But Not MSOPPE, Attenuated Amphetamine-stimulated pCREB, pElk-1, pERK1/2, and Fos Immunoreactivity}

Since amphetamine phosphorylated CREB, Elk-1, and ERK1/2, the group I (PHCCC) or group II/III antagonist (MSOPPE) was infused intrastriatally to test whether group I mGluRs couple amphetamine to CREB, Elk-1, ERK1/2 phosphorylation and Fos induction in the striatum. Fos was added in this experiment to detect concurrent changes in inducible gene expression as a result of the induction of phosphoproteins. In the medial region of the striatum, low basal levels of pCREB (Figure 4, panel A), pElk-1 (Figure 4, panel E), and Fos (Figure 4, panel M) IR were seen in rat received saline. Neither $\mathrm{PH}-$ CCC nor MSOPPE infusion alone altered basal levels of pCREB, pElk-1, and Fos IR. P-ERK1/2 IR was not detected in rat treated with saline (Figure 4, panel I), PHCCC, or MSOPPE. Acute injection of amphetamine significantly increased pCREB (Figure 4, panel B), pElk-1 (Figure 4, panel F), pERK1/2 (Figure 4, panel J), and Fos (Figure 4, panel N) IR as compared with controls. In the presence of PHCCC, amphetamine induced much less induction of pCREB (Figure 4, panel C), pElk-1 (Figure 4, panel G), pERK1/2 (Figure 4, panel K), and Fos (Figure 4, panel O) IR. In contrast to PHCCC, MSOPPE did not alter amphetamine-induced increases in the immunoreactivity of all the 4 markers. Like pCREB and pElk-1 IR, Fos IR induced by amphetamine was exclusively confined to the nuclear compartments of striatal neurons. Semi-quantitation confirmed that amphetamine increased the immunoreactivity of all the markers in the medial striatum, which was blocked by pretreatment with PHCCC, but not MSOPPE (Figure 4, panels D, H, L, and $P)$. Similar results were obtained in the lateral region of the striatum, which are illustrated in Figure 5.

\section{MPEP Attenuated Amphetamine-stimulated pCREB, pElk-1, pERK1/2, and Fos Immunoreactivity}

A separate study was carried out to evaluate the importance of mGluR5 in the amphetamine action. From Figure 6, i.p. injection of MPEP alone at the two doses (1 and $10 \mathrm{mg} / \mathrm{kg}$ ) had no significant effects on basal levels of pCREB, pElk-1, pERK1/2, and Fos IR in the dorsal striatum. MPEP at the lower dose $(1 \mathrm{mg} / \mathrm{kg})$ did not alter amphetamine-stimulated phosphorylation of the three phosphoproteins and Fos induction in the dorsal striatum. However, MPEP at the higher dose $(10 \mathrm{mg} /$ $\mathrm{kg}$ ) significantly attenuated pCREB, pElk-1, pERK, and Fos IR induced by amphetamine. 

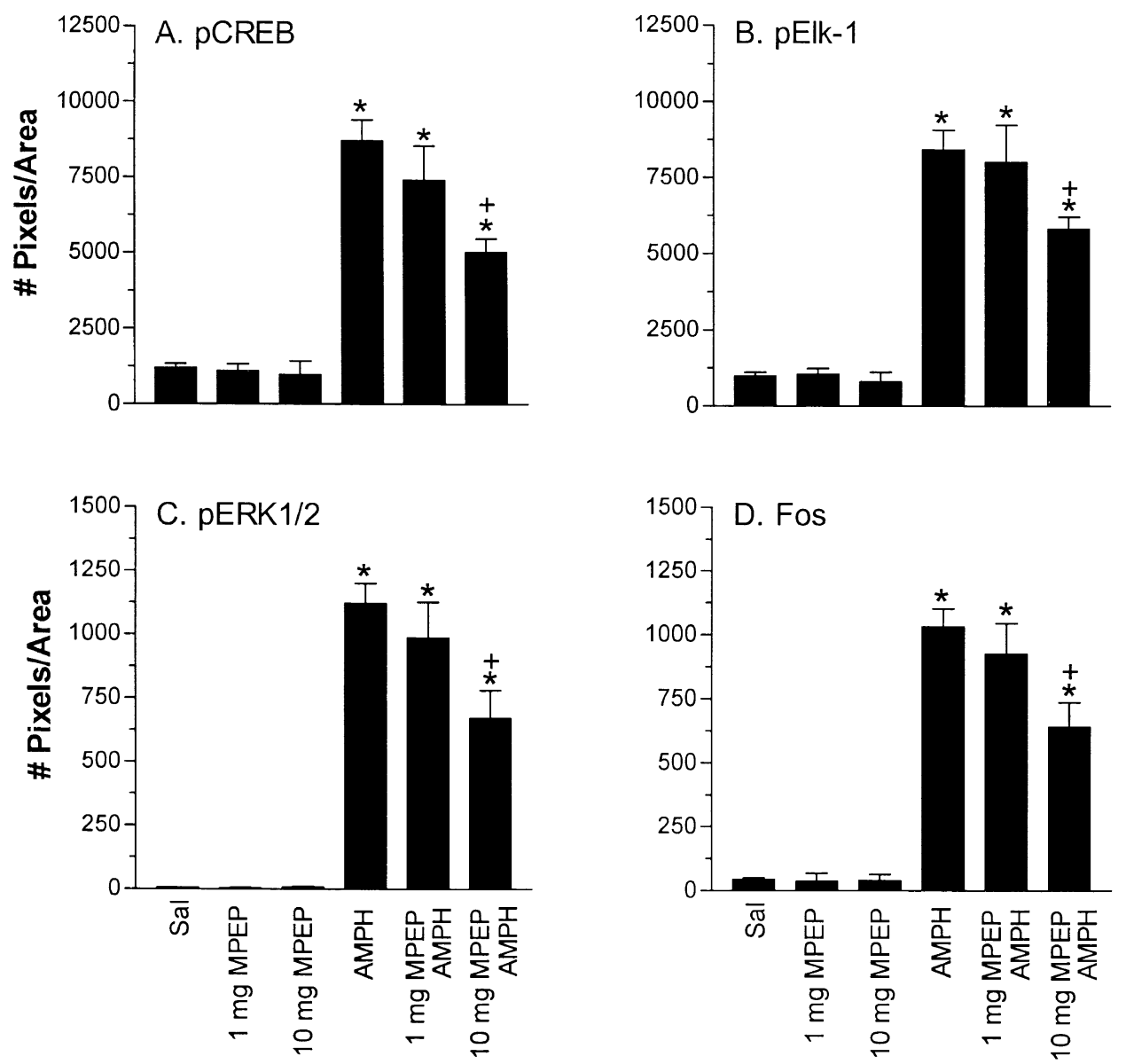

Figure 6. Semi-quantitative analysis of the effect of i.p. injection of MPEP on an acute amphetamine-stimulate pCREB (A), pElk-1 (B), pERK1/2 (C), and Fos (D) induction in the dorsal striatum $(n=4$ per group). MPEP (1 or $10 \mathrm{mg}$ / $\mathrm{kg}$ ) was given alone or $30 \mathrm{~min}$ prior to amphetamine (5 mg/ kg, i.p.). *p $<.001$ as compared with saline group; ${ }^{+} \mathrm{p}<.001$ as compared with amphetaminetreated group.
Dantrolene Did Not Alter Amphetamine-stimulated pCREB, pElk-1, pERK1/2, and

Fos Immunoreactivity

Ryanodine receptors are known to mediate intracellular $\mathrm{Ca}^{2+}$ release that may participate in the regulation of CREB, Elk-1 and ERK1/2 phosphorylation and Fos induction in response to amphetamine stimulation. In this study, dantrolene ( 2 or $20 \mathrm{nmol}$ ) that blocks intracellular $\mathrm{Ca}^{2+}$ release from ryanodine-sensitive stores was infused into the dorsal striatum to evaluate whether ryanodine-sensitive stores couple amphetamine to CREB, Elk-1, and ERK1/2 phosphorylation and Fos induction in the striatum, and the results from semi-quantitative analysis are shown in Figure 7. Saline or $20 \mathrm{nmol}$ dantrolene alone had no effect on basal levels of pCREB, pElk-1, pERK1/2, and Fos IR. Neither 2 nor 20 nmol dantrolene altered amphetamine-induced increases in pCREB, pElk-1, pERK1/2, and Fos IR in both medial and lateral regions of the striatum.

\section{DISCUSSION}

In the present study, acute amphetamine increased the phosphorylation of CREB, Elk-1, ERK1/2 and Fos gene expression in the striatum. Since the phosphorylation was attenuated by the group I mGluR antagonist PHCCC as well as the mGluR5 antagonist MPEP, activation of group I mGluRs is important for a full capacity of amphetamine to phosphorylate these signaling proteins. The calcium release from ryanodine-sensitive stores did not seem to play a significant role in this event because the ryanodine receptor antagonist dantrolene was ineffective to alter amphetamine effects.

The present results showed that amphetamine increased the immunoreactivity of pCREB, pElk-1, and pERK1/2 in the striatum. Previous studies demonstrate that amphetamine increases the phosphorylation of CREB in the striatum (Konradi et al. 1994). The AC activator, forskolin, and cAMP analogs activate the ERK1/ 2 cascades in hippocampal and striatal neurons (Vossler et al. 1997; de Rooij et al. 1998; Kawasaki et al. 1998; Vincent et al. 1998; Impey et al. 1998; Choe and McGinty 2000). A recent study shows that cocaine or methamphetamine upregulates pERK1/2 IR in the striatum (Adams et al. 2001). These findings suggest that dopamine stimulation is capable of activating the ERK1/2 signaling pathway, which may be involved in subsequent facilitation of CREB and Elk-1 phosphorylation.

In addition to dopamine $\left(\mathrm{D}_{1}\right)$ receptors, activation of group I mGluRs increases ERK1/2 phosphorylation in 

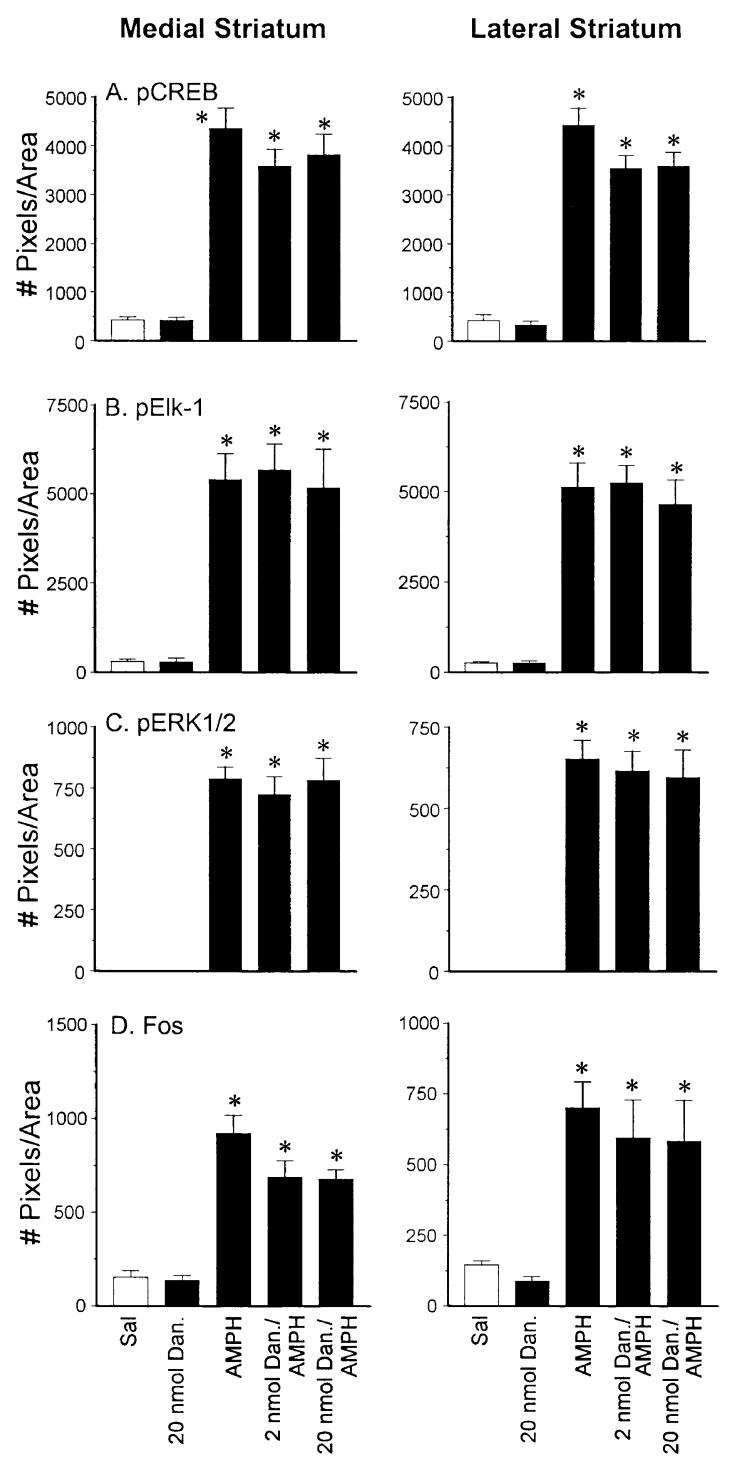

Figure 7. Semi-quantitative analysis of the effect of intrastriatal infusion of 2 or $20 \mathrm{nmol}$ dantrolene on an acute amphetamine-stimulated pCREB (A), pElk-1 (B), pERK1/2 (C), and Fos (D) immunoreactivity in the medial and lateral areas of the striatum ( $n=4-5$ per group). Intrastriatal dantrolene was given alone or $30 \mathrm{~min}$ prior to amphetamine (5 mg/kg, i.p.). Neither 2 nor $20 \mathrm{nmol}$ dantrolene altered amphetamine (AMPH, $5 \mathrm{mg} / \mathrm{kg}$, i.p.)-stimulated immunoreactivity of all the markers. ${ }^{*} p<.001$ as compared with saline group.

the spinal cord (Karim et al. 2001), primary astrocytes (Schinkmann et al. 2000), glial cell cultures (Peavy and Conn 1998), and the striatum (Choe and Wang 2001). Similarly, mGluR1a mediates phosphorylation of ERK2 in Chinese hamster ovary cells transfected with rat mGluRs (Ferraguti et al. 1999) and rat cortical cultures (Fiore et al. 1993). ERK1/2 has been found to be a major kinase phosphorylating CREB and Elk-1. For instance, ERK cascades couple CREB phosphorylation in CA1 area of hippocampus (Roberson et al. 1999). Activation of ERK1/2 by $\mathrm{Ca}^{2+}$ influx increases CREB phosphorylation in PC12 cells and hippocampal neurons (Impey et al. 1998). ERK1/2 is also found to mediate glutamateinduced phosphorylation of transcription factors because the ERK1/2 kinase inhibitor, PD98059, attenuates glutamate-stimulated CREB and Elk-1 phosphorylation in striatal slices (Vanhoutte et al. 1999) and the striatum (Sgambato et al. 1998; Davis et al. 2000; Choe and McGinty 2001). Thus, in striatal neurons, ERK1/2 may represent an effector downstream to glutamate receptors that phosphorylates transcription regulators CREB and Elk-1. In this study, blockade of group I mGluRs by PHCCC decreased amphetamine-stimulated pCREB, pElk-1, pERK1/2, and Fos IR in both medial and lateral areas of the striatum. In contrast, blockade of group II/ III mGluRs did not affect the immunoreactivity of all the markers. Thus, group I mGluR-sensitive ERK1/2 activation may participate in the amphetamine-stimulated pCREB and pElk-1 induction. Further studies are needed to test effects of the blockade of ERK1/2 activation with PD98059 on the amphetamine phosphorylation of CREB/Elk-1 in order to provide direct evidence to argue for or against this notion.

Parallel to upregulation of pCREB and pElk-1 induction, Fos induction was increased in this study, suggesting a possible transcriptional role of pCREB and pElk-1 in inducible $c$-fos gene expression. This is supported by the finding that knock down of CREB by antisense oligonucleotides against CREB attenuates $c$-fos induction in the striatum in vivo (Konradi et al. 1994).

Blockade of intracellular $\mathrm{Ca}^{2+}$ release from ryanodine-sensitive stores by dantrolene did not affect amphetamine-stimulated pCREB, pElk-1, pERK1/2, and Fos IR in both medial and lateral regions of the dorsal striatum. These data indicate that intracellular $\mathrm{Ca}^{2+}$ release from ryanodine-sensitive stores may not be involved in amphetamine-stimulated increases in the regulatory proteins of ERK1/2 pathways. It is therefore possible that $\mathrm{Ca}^{2+}$ release from $\mathrm{IP}_{3}$-sensitive stores and/or enhanced $\mathrm{Ca}^{2+}$ influx via NMDA receptors or L-type voltage-operated $\mathrm{Ca}^{2+}$ channels may contribute to the activation of ERK1/2 pathways in the striatum. This is supported by the findings that stimulation of mGluR1a potentiates N-methyl-D-Aspartate (NMDA) channel activity through protein kinase C (Alagarsamy et al. 1999; Hisatsune et al. 1997; Choe and Wang 2002). NMDA receptor activation phosphorylates ERK1/2 or CREB, which is prevented by NMDA receptor blockade in cultured rat cortical (Jiang et al. 2000) or striatal (Das et al. 1997) neurons and rat hippocampus (Ahn et al. 2000).

In summary, the results obtained from this study and others indicate a glutamate receptor scenario in mediating amphetamine effects on signaling proteins and gene expression. This scenario initiates with in- 
creased glutamate release in the striatum after amphetamine stimulation (Del Arco et al. 1999; Nash and Yamamoto 1993; Rawls and McGinty 2000). Released glutamate increases intracellular $\mathrm{Ca}^{2+}$ levels via both group I mGluR-dependent $\mathrm{Ca}^{2+}$ mobilization and NMDA- and/or AMPA/kainate-dependent $\mathrm{Ca}^{2+}$ influx. When spatially and temporally modified $\mathrm{Ca}^{2+}$ signal reaches a high enough level, it facilitates the phosphorylation of various protein kinases, including $\mathrm{Ca}^{2+} /$ calmodulin-dependent protein kinases and ERK1/2. Activated protein kinases can then phosphorylate transcription factors, such as CREB and Elk-1, to alter gene transcription. In addition to this glutamate cascade, a well-known dopamine $\mathrm{D}_{1} / \mathrm{cAMP} /$ protein kinase $\mathrm{A}$ cascade is another effective pathway phosphorylating CREB/Elk-1 and inducing gene expression. Obviously, there are considerable cross-talks among different signaling pathways at receptor and post-receptor levels. These cross-talks sophisticatedly control gene expression in response to cellular stimulation under different conditions. Further studies need to unravel interactions among these signaling proteins that forms different biochemical apparatuses inducing different gene expression under different conditions.

\section{ACKNOWLEDGMENTS}

This study was supported by grants from the NIH (DA10355 and MH61469) and the University of Missouri-Research Board.

\section{REFERENCES}

Adams DH, Hanson GR, Keefe KA (2001): Psychostimulants activate p42/44 MAPK in dorsal and ventral striatum. Soc Neurosci Abstr 27:445.2

Ahn YM, Oh SW, Kang UG, Park J, Kim YS (2000): An N-methyl-D-aspartate antagonist, MK-801, preferentially reduces electroconvulsive shock-induced phosphorylation of p38 mitogen-activated protein kinase in the rat hippocampus. Neurosci Lett 296:101-104

Alagarsamy S, Marino MJ, Rouse ST, Gereau RW, Heinemann SF, Conn PJ (1999): Activation of NMDA receptors reverses desensitization of mGluR5 in native and recombinant systems. Nat Neurosci 2:234-240

Cartmell J, Monn JA, Schoepp DD (1999): The metabotropic glutamate 2/3 receptor agonists LY354740 and LY379268 selectively attenuate phencyclidine versus $\mathrm{d}$-amphetamine motor behaviors in rats. J Pharmacol Exp Ther 291:161-170

Cartmell J, Monn JA, Schoepp DD (2000): The mGlu(2/3) receptor agonist LY379268 selectively blocks amphetamine ambulations and rearing. Eur J Pharmacol 400:221-224

Choe ES, McGinty JF (2000): N-Methyl-D-aspartate receptors and p38 mitogen-activated protein kinase are required for cAMP-dependent cyclase response element binding protein and Elk-1 phosphorylation in the striatum. Neuroscience 101:607-617

Choe ES, McGinty JF (2001): Cyclic AMP and mitogen-activated protein kinases are required for glutamate-dependent cyclic AMP response element binding protein and Elk-1 phosphorylation in the dorsal striatum in vivo. J Neurochem 76:401-412

Choe ES, Wang JQ (2001): Group I metabotropic glutamate receptor activation increases phosphorylation of cAMP response element-binding protein, extracellular signalregulated kinases, and Elk-1 in rat dorsal striatum. Mol Brain Res 94:75-84

Choe ES, Wang JQ (2002): Regulation of transcription factor phosphorylation by metabotropic glutamate receptorassociated signaling pathways in rat striatal neurons. Neuroscience (in press)

Dale LB, Babwah AV, Bhattacharya M, Kelvin DJ, Ferguson SS (2001): Spatial-temporal patterning of metabotropic glutamate receptor-mediated Inositol 1,4,5-triphosphate, calcium, and protein kinase C oscillations: Protein kinase C-dependent receptor phosphorylation is not required. J Biol Chem 276:35900-35908

Das S, Grunert M, Williams L, Vincent SR (1997): NMDA and D1 receptors regulate the phosphorylation of CREB and the induction of $c$-fos in striatal neurons in primary culture. Synapse 25:227-233

Davis S, Vanhoutte P, Pages C, Caboche J, Laroche S (2000): The MAPK/ERK cascade targets both Elk-1 and cAMP response element-binding protein to control long-term potentiation-dependent gene expression in the dentate gyrus in vivo. J Neurosci 20:4563-4572

de Rooij J, Zwartkruis FJ, Verheijen MH, Cool RH, Nijman SM, Wittinghofer A, Bos JL (1998): Epac is a Rap1 guanine-nucleotide-exchange factor directly activated by cyclic AMP. Nature 396:474-477

Del Arco A, Gonzalez-Mora JL, Armas VR, Mora F (1999): Amphetamine increases the extracellular concentration of glutamate in striatum of the awake rat: involvement of high affinity transporter mechanisms. Neuropharmacology 38:943-954

Ferraguti F, Baldani-Guerra B, Corsi M, Nakanishi S, Corti C (1999): Activation of the extracellular signal-regulated kinase 2 by metabotropic glutamate receptors. Eur J Neurosci 11:2073-2082

Fiore RS, Murphy TH, Sanghera JS, Pelech SL, Baraban JM (1993): Activation of p42 mitogen-activated protein kinase by glutamate receptor stimulation in rat primary cortical cultures. J Neurochem 61:1626-1633

Hisatsune C, Umemori H, Inoue T, Michikawa T, Kohda K, Mikoshiba K, Yamamoto T (1997): Phosphorylationdependent regulation of $\mathrm{N}$-methyl-D-aspartate receptors by calmodulin. J Biol Chem 272:20805-20810

Impey S, Obrietan K, Wong ST, Poser S, Yano S, Wayman G, Deloulme JC, Chan G, Storm DR (1998): Cross talk between ERK and PKA is required for $\mathrm{Ca}^{2+}$ stimulation of CREB-dependent transcription and ERK nuclear translocation. Neuron 21:869-883

Jiang Q, Gu Z, Zhang G, Jing G (2000): N-methyl-D-aspartate receptor activation results in regulation of extracellular signal-regulated kinases by protein kinases and 
phosphatases in glutamate-induced neuronal apototiclike death. Brain Res 887:285-292

Karim F, Wang CC, Gereau RW (2001): Metabotropic glutamate receptor subtypes 1 and 5 are activators of extracellular signal-regulated kinase signaling required for inflammatory pain in mice. J Neurosci 21:3771-3779

Kawabata S, Kohara A, Tsutsumi R, Itahana H, Hayashibe S, Yamaguchi T, Okada M (1998): Diversity of calcium signaling by metabotropic glutamate receptors. J Biol Chem 273:17381-17385

Kawasaki H, Springett GM, Mochizuki N, Toki S, Nakaya M, Matsuda M, Housman DE, Graybiel AM (1998): A family of cAMP-binding proteins that directly activate Rap1. Science 282:2275-2279

Konradi C, Cole RL, Heckers S, Hyman SE (1994): Amphetamine regulates gene expression in rat striatum via transcription factor CREB. J Neurosci 14:5623-5634

Mao L, Wang JQ (1999): Protection against acute amphetamine-induced behavior by microinjection of a group II metabotropic glutamate receptor agonist into the dorsal striatum of rats. Neurosci Lett 270:103-106

Mao L, Wang JQ (2000): Distinct inhibition of acute cocainestimulated motor activity following microinjection of a group III metabotropic glutamate receptor agonist into the dorsal striatum of rats. Pharmacol Biochem Behav 67:93-101

Mao L, Lau YS, Wang JQ (2000): Activation of group III metabotropic glutamate receptors inhibits basal and amphetamine-stimulated dopamine release in rat dorsal striatum: an in vivo microdialysis study. Eur J Pharmacol 404:289-297

Nash JF, Yamamoto BK (1993): Effect of D-amphetamine on the extracellular concentrations of glutamate and dopamine in iprindole-treated rats. Brain Res 627:1-8

Peavy RD, Conn PJ (1998): Phosphorylation of mitogen-activated protein kinase in cultured rat cortical glia by stimulation of metabotropic glutamate receptors. J Neurochem 71:603-612

Rawls SM, McGinty JF (2000): Delta opioid receptors regulate calcium-dependent, amphetamine-evoked glutamate levels in the rat striatum: an in vivo microdialysis study. Brain Res 861:296-304

Roberson ED, English JD, Adams JP, Selcher JC, Kondratick C, Sweatt JD (1999): The mitogen-activated protein kinase cascade couples PKA and PKC to cAMP response element binding protein phosphorylation in area CA1 of hippocampus. J Neurosci 19:4337-4348

Schinkmann KA, Kim TA, Avraham S (2000): Glutamatestimulated activation of DNA synthesis via mitogenactivated protein kinase in primary astrocytes: involvement of protein kinase $C$ and related adhesion focal tyrosine kinase. J Neurochem 74:1931-1940

Schnabel R, Kilpatrick IC, Collingridge GL (1999): An investigation into signal transduction mechanisms involved in DHPG-induced LTD in the CA1 region of the hippocampus. Neuropharmacology 38:1585-1596

Sgambato V, Pages C, Rogard M, Besson MJ, Caboche J (1998): Extracellular signal-regulated kinase (ERK) controls immediate early gene induction on corticostriatal stimulation. J Neurosci 18:8814-8825

Simpson JN, Wang JQ, McGinty JF (1995): Repeated amphetamine administration induces a prolonged augmentation of phosphorylated cyclase response element-binding protein and Fos-related antigen immunoreactivity in rat striatum. Neuroscience 69:441-457

Spooren WP, Gasparini F, Bergmann R, Kuhn R (2000): Effects of the prototypical mGlu(5) receptor antagonist 2-methyl-6-(phenylethynyl)-pyridine on rotarod, locomotor activity and rotational responses in unilateral 6-OHDA-lesioned rats. Eur J Pharmacol 406:403-410

Testa CM, Standaert DG, Young AB, Penney JB Jr (1994): Metabotropic glutamate receptor mRNA expression in the basal ganglia of the rat. J Neurosci 14:3005-3018

Wang JQ, Mao L (2000): Sustained behavioral stimulation following selective activation of group I metabotropic glutamate receptors in rat striatum. Pharmacol Biochem Behav 65:439-447

Vanhoutte P, Barnier JV, Guibert B, Pages C, Besson MJ, Hipskind RA, Caboche J (1999): Glutamate induces phosphorylation of Elk-1 and CREB, along with $c$-fos activation, via an extracellular signal-regulated kinasedependent pathway in brain slices. Mol Cell Biol 19:136-146

Vincent SR, Sebben M, Dumuis A, Bockaert J (1998): Neurotransmitter regulation of MAP kinase signaling in striatal neurons in primary culture. Synapse 29:29-36

Vossler MR, Yao H, York RD, Pan MG, Rim CS, Stork PJ (1997): cAMP activates MAP kinase and Elk-1 through a B-Raf- and Rap1-dependent pathway. Cell 89:73-82 